\title{
Removal of Polymers with Various Chemical Structures using Wet Ozone
}

\author{
Yousuke Goto $^{\text {a, *, Kyouya Kitano }}{ }^{\text {a, }}$, Takeshi Maruokaa, Masashi Yamamotoa, \\ Akihiko Kono $^{a}$, Hideo Horibe ${ }^{a}$, and Seiichi Tagawa ${ }^{b}$
a. Research Laboratory for Integrated Technological Systems, Kanazawa Institute of Technology, Yatsukaho, Hakusan, Ishikawa 924-0838, Japan
b. The Institute of Scientific and Industrial Research, Osaka University, Mihogaoka, Ibaraki, Osaka 567-0047, Japan
E-mail:hhoribe@neptune.kanazawa-it.ac.jp

\begin{abstract}
We evaluated the chemical reactivity of wet ozone and polymers by estimating removal of polymers with various chemical structures using wet ozone. The removal rates of polymers that have the carbon-carbon double bond ( $\mathrm{C}-\mathrm{C}$ double bond) in the main chain (novolak resin, cis-1,4-polyisoprene) were the fastest. The removal rates of polymers that have a C-C double bond in the side chain (PVP, PS) were slower than those of novolak resin and cis-1,4-polyisoprene. Polymers with no $\mathrm{C}$-C double bond (PMMA, PVC) were not removed. We believe that wet ozone should react easily with $\mathrm{C}-\mathrm{C}$ double bonds. The main chain of novolak resin and that of cis-1,4-polyisoprene should be decomposed by reaction with wet ozone. In PVP and PS, the benzene ring in the side chain changes into carboxylic acid by reaction with wet ozone. Therefore, the dissolution ability of PVP and PS to water should increase. Keywords: chemical structures, removal, wet ozone, polymer, environment.
\end{abstract}

\section{Introduction}

Resist removal from substrates in a semiconductor manufacturing process conventionally makes use of oxygen plasma and/or chemicals (e.g., a sulfuric acid hydrogen peroxide mixture, and an ammonia hydrogen peroxide mixture). These environmentally unfriendly chemicals are used in large amounts and so cause environmental damage [1,2].

As method of not using those chemicals, ozone with high oxidation potential is expected to remove the resist and organic residue. However, the resist cannot be removed using ozone alone. The dry process using ozone requires temperatures higher than $250^{\circ} \mathrm{C}$ in order to generate oxygen radicals from the ozone by thermal decomposition. From this reason, the process using ozone may oxidize substrates and metal wiring $[3,4]$.

We examined a low-temperature wet-ozone process that environmentally friendly. In the wet-ozone process, ozone gas mixed with a little water was irradiated to the resist at a temperature below $100^{\circ} \mathrm{C}$, and the resist is converted to a carboxylic acid by the ozone and the condensed water [5-8].

Miniaturizing patterns is also a serious problem in semiconductor manufacturing process. The resist resolution is enhanced by shortening the exposure wavelength. Therefore, a $\mathrm{KrF}$ excimer laser $(248 \mathrm{~nm})$ and an ArF excimer laser (193nm) are used in semiconductor manufacturing process. However, the benzene ring in novolak resin of the base polymer of resist for $\mathrm{g} / \mathrm{i}$-ray absorbs the light of nearly $240 \mathrm{~nm}$. Therefore, it is impossible to expose by the light with wavelengths of $248 \mathrm{~nm}$ and $193 \mathrm{~nm}$. This is why polyvinyl phenol (PVP) is used as the base polymer for $\mathrm{KrF}$ resist. Also, polymethyl methacrylate (PMMA) is used as the base polymer for ArF resist.

We evaluated the chemical reactivity of wet ozone with

\begin{tabular}{lll}
\hline Received & April & 1, 2010 \\
Accepted & May & 7, 2010
\end{tabular}


chemical structures of polymers by estimating the removal of polymers with various chemical structures using wet ozone.

\section{Experimental}

Figure 1 presents a diagram of the experiment apparatus for wet ozone (Mitsubishi Electric-Corp. and SPC Electronics Corp.). Ozone gas mixed with a little water (wet ozone) is generated by bubbling ozone gas through hot water. Also, a little water condenses on the resist due to the difference in temperature $\left(\triangle T=T_{1}-T_{2}\right)$ between wet ozone $\left(T_{1}\right)$ and the Si wafer $\left(T_{2}\right)$. The amount of water condensed on the resist was controlled by adjusting this temperature difference [9].

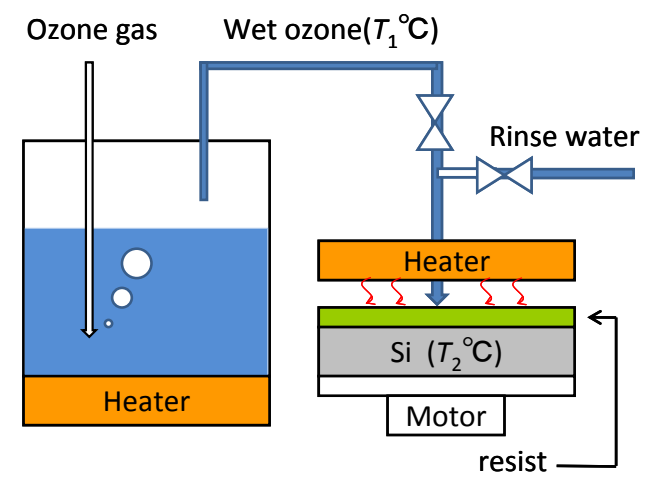

Fig. 1 Experiment apparatus for resist removal using wet ozone

Figure 2 presents the chemical reaction of a carbon-carbon double bond (C-C double bond) with ozone and the hydrolysis of ozonide. In resist removal using wet ozone, the $\mathrm{C}-\mathrm{C}$ double bond in the benzene ring of the resist reacts with the ozone, and ozonide is generated. Ozonide is hydrolyzed and generates carboxylic acid [10]. Finally, the carboxylic acid is washed down from the $\mathrm{Si}$ wafer by pure water (rinse).

Three processes (wet-ozone irradiation, pure-water washing, and drying) were repeated in each cycle of the removal using wet ozone. The removal rate was calculated by dividing the initial polymer thickness by the wet ozone irradiation time for which the polymer was completely removed. The cycle consisted of $10 \mathrm{~s}$ at 2000rpm for wet-ozone irradiation, $5 \mathrm{~s}$ at 2000rpm for pure-water washing, and 20s at 1000rpm for drying. The ozone gas concentration was $230 \mathrm{~g} / \mathrm{m}^{3}(10.2 \mathrm{vol} \%)$, and flow rate was $12.5 \mathrm{sm}$. The wet ozone temperature was $T_{1}=60^{\circ} \mathrm{C}$, and the $\mathrm{Si}$ wafer temperature was $T_{2}=50^{\circ} \mathrm{C}$.

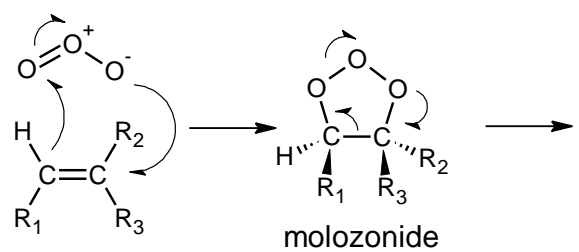<smiles>[R]C([B])=[O+][O-]</smiles>

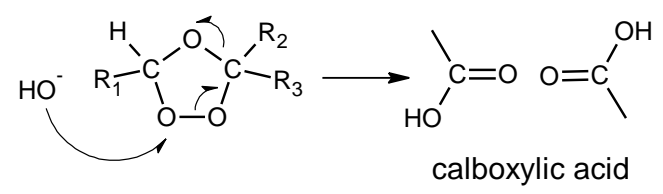

Fig. 2 Chemical reaction of C-C double bond with ozone and the hydrolysis of ozonide

We used the polymers that dissolved with solvents. These polymers were spin-coated onto a $\mathrm{Si}$ wafer using a spin coater (ACT-300A; Active) at 2000rpm for 20sec and pre-baked at $100^{\circ} \mathrm{C}$ for $1 \mathrm{~min}$ on a hotplate (PMC 720 series; Dataplate). Table 1 lists polymers, solvents, and film thicknesses for this study. Figure 3 presents the estimated chemical structures of polymers. Novolak resin and cis-1,4-polyisoprene that have a C-C double bond in the main chain, polyvinyl phenol (PVP) and polystyrene (PS) that have a C-C double bond in the side chain, polymethyl methacrylate (PMMA) and polyvinyl chloride (PVC) that do not have a C-C double bond were estimated. We also performed removal of a positive-tone novolak photoresist (AZ6112; AZ-Electronic Materials) as a reference.

Table 1 Film thickness, polymers and solvents

\begin{tabular}{|c|c|}
\hline Polymer samples/Solvents & Thickness $[\mu \mathrm{m}]$ \\
\hline AZ6112 & 1.35 \\
\hline novolak resin $\left(\mathrm{M}_{\mathrm{w}}=15000\right) / \mathrm{PGMEA}$ & 0.96 \\
\hline $\begin{array}{c}\text { cis-1,4-polyisoprene }\left(\mathrm{M}_{\mathrm{w}}=38000\right) / \\
\text { Xylene }\end{array}$ & 0.40 \\
\hline PVP( $\left(M_{w}=20000\right) /$ Ethyl lactate & 1.62 \\
\hline PS $\left(\mathrm{M}_{\mathrm{w}}=4000 \sim 20000\right) /$ Toluene & 0.66 \\
\hline $\operatorname{PMMA}\left(\mathrm{M}_{\mathrm{w}}=96700\right) /$ Ethyl lactate & 1.30 \\
\hline $\operatorname{PVC}\left(\mathrm{M}_{\mathrm{w}}=68750\right) /$ Cyclohexanone & 1.32 \\
\hline
\end{tabular}


<smiles>Cc1ccc(C(C)(C)C)c(O)c1CC(C)(C)C</smiles><smiles>CC(=CCC(C)(C)C)CCCC(C)(C)C</smiles>

novolak resin

cis-1,4-polyisoprene<smiles>CC(C)(C)CCc1ccc(O)cc1</smiles>

PVP<smiles>CC(C)(C)CCC(CC(C)(C)C)c1ccccc1</smiles>

PS<smiles>CCCC1COC(=O)C1(C)CCC</smiles><smiles>CC(C)C(Cl)CC(C)(C)C</smiles>

PMMA

Fig. 3 Chemical structures of polymers estimated for this study

\section{Results and Discussions}

Figure 4 plots the results of the removal of polymers using wet ozone. Table 2 presents removal rates of each polymer using wet ozone. The removal rates of polymers that have a C-C double bond in main chain (novolak resin, cis-1,4-polyisoprene) were fastest. The removal rates of polymers that with a C-C double bond in the side chain (PVP, PS) were slower than those of novolak resin and cis-1,4-polyisoprene. However, polymers with no C-C double bond (PMMA, PVC) were not removed.

The main chains of novolak resin and cis-1,4-polyisoprene should be decomposed by reaction with wet ozone.

In PVP and PS, the benzene ring in the side chain was converted into carboxylic acid by reaction with wet ozone. Thus, PVP and PS should be removed because the dissolution ability of PVP and PS to water increased.

We also discuss this consideration in terms of solubility parameters (SP). Table 3 lists the SP of polymers that were estimated. The SP was calculated using the estimation technique of Fedor [11]. Polyacrylic acid has a carboxyl group in its side chain. Therefore, the dissolution ability of PVP and PS to water should increase because the SP of generated polymers nears the SP of water due to the reaction of wet ozone with the C-C double bond.

PMMA and PVC should not be removed because these polymers do not include a C-C double bond.

While novolak resin and cis-1,4-polyisoprene were removed by decomposition of their main chains, PVP and
PS were removed because their dissolution ability to water increased due to the benzene ring changing to carboxylic acid. Therefore, the removal rates of novolak resin and cis-1,4-polyisoprene are faster than those of $\mathrm{PVP}$ and PS.

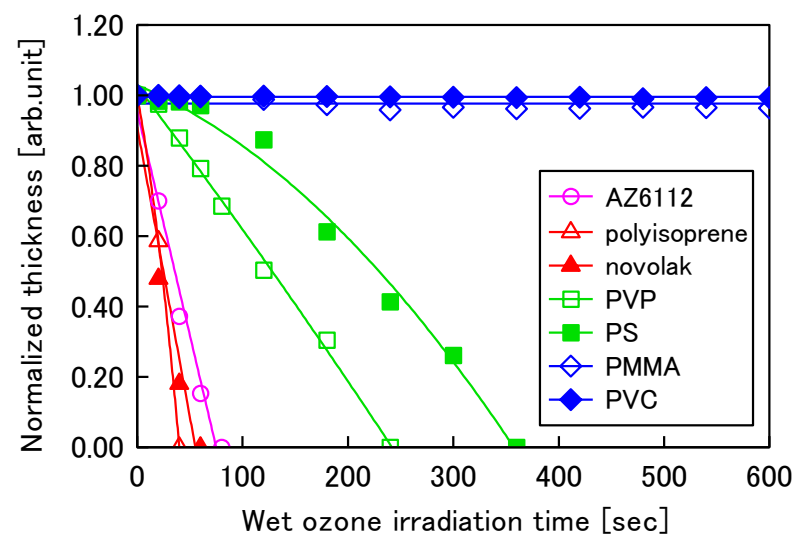

Fig. 4 Dependence of polymer normalized thickness on wet ozone irradiation time

Table 2 Removal rate of polymers with various chemical structures using wet ozone

\begin{tabular}{cc}
\hline Polymer sample & \multicolumn{2}{c}{ Removal rate $[\mu \mathrm{m} / \mathrm{min}]$} \\
\hline AZ6112 & 1.01 \\
\hline novolak resin & 0.96 \\
cis-1,4-polyisoprene & 0.61 \\
PVP & 0.35 \\
PS & 0.12 \\
PMMA & 0.01 \\
PVC & 0 \\
\hline
\end{tabular}

Table 3 Solubility parameters of estimated polymers

\begin{tabular}{cc}
\hline Polymer sample & $\begin{array}{c}\text { Solubility Parameter } \\
{\left[\left(\mathrm{J} / \mathrm{cm}^{3}\right)^{1 / 2}\right]}\end{array}$ \\
\hline $\mathrm{H}_{2} \mathrm{O}$ & 41.0 \\
\hline PVP & 27.8 \\
PS & 21.6 \\
Polyacrylic acid & 28.7 \\
\hline
\end{tabular}

\section{Conclusion}

We performed removal of polymers with various chemical structures using wet ozone.

1) The removal rates of novolak resin and cis-1,4-polyisoprene are faster than those of PVP and PS. PMMA and PVC were not removed. 
2) Novolak resin and cis-1,4-polyisoprene should be removed by decomposition of the main chain.

3) PVP and PS should be removed because the dissolution ability of PVP and PS to water increased when the benzene ring was converted into carboxylic acid.

4) PMMA and PVC should not be removed because these polymers do not include a C-C double bond.

\section{References}

1) M. Yamamoto, T. Maruoka, A. Kono, H. Horibe, and H. Umemoto, Jpn. J. Appl. Phys. 49 (2010) 016701

2) M. Yamamoto, T. Maruoka, Y. Goto, A. Kono, H. Horibe, M. Sakamoto, E. Kusano, H. Seki, and S. Tagawa., J. Electrochem. Soc., 157(3), H361-H370 (2010)

3)Huynh,C.K,;Mitchener,J.C.,J.Vac.Sci.Technol, 1991,B9(2),353-356.

4) Gardner,W.L.; Baddorf,A.P.; Holber,W.M., J.Vac.Sci.Technol., 1997, A15(3), 1409-1412.
5) S.Noda, M.Miyamoto, H.Horibe, I.Oya, M.Kuzumoto, and T.Kataoka, J. Electrochem. Soc., 150(9), 537-542 (2003)

6) S. Noda, K. Kawase, H. Horibe, I. Oya, M. Kuzumoto, and T. Kataoka, J. Electrochem.

Soc., 152(1), G73-G82 (2005)

7) H. Horibe, M. Yamamoto, Y. Goto, T. Miura, and S. Tagawa, Jpn. J. Appl. Phys. 48 (2009) 026505

8) M. Yamamoto, Y. Goto, T. Maruoka, H. Horibe, T. Miura, E. Kusano, and S. Tagawa, J. Electrochem. Soc., 156(7), H505-H511 (2009)

9) H.Horibe, M.Yamamoto, T.Ichikawa, T.Kamimura and S.Tagawa., J. Photopolymer Science and Technology, 20, 315-318 (2007)

10) L.GWade,Jr, Organic-chemistry 6th ed, Pearson Prentice Hall (2006), pp360-362

11) H. Yamamoto, "SP-chi kiso-ouyou to keisanhouhou", Johokiko.Co.LTD.(2005), pp66-67 (in Japanese) 